\title{
Contents of Opticheskii Zhurnal (Journal of Optical Technology), vol. 76, no. 7, 2009
}

PACS numbers: 01.10.Cr

DOI: $10.1134 /$ S0030400X0907025X

The following papers will be published in the July issue of Opticheskiu Zhurnal (Journal of Optical Technology), vol. 76, no. 7, 2009.

Physical Optics. Fluorescence 4-Dimethylaminochalcon Probe: Development and Application of Techniques for Investigating Solvatochromism and Solvatofluorochromism Regularities (N.G. Bakhshiev, S.K. Gudaryan, G.E. Dobretsov, A.Yu. Kirillova, and V.Yu. Svetlichnyi).

Laser Physics and Technology. Nonlinear Optical Response of Semiconductor Nanoparticles with Metal Shells at a 1.06- $\mu \mathrm{m}$ Wavelength (A.I. Sidorov, O.P. Vinogradova, and O.V. Bandyuk); Laser Cleaning of Gold-Plated Bronze Surfaces (S. Siano, F. Graciü, and V.A. Parfenov).

Computation, Design, and Manufacture of Optical Systems. Technique for Designing Initial Systems for Thermal Imaging Objective Lenses (A.P. Grammatin and K.T. Chan); Image Tilt Correction in Optical Systems (G.S. Polishchuk and M.N. Sokol'skiū); Use of a Point Radiation Source for Enhancing the Functional Capabilities of a Displacement Meter (I.P. Miroshnichenko, A.G. Serkin, and V.P. Sizov); Properties of
Optical Systems Containing Decentered Planoid Elements in the Third-Order Aberration Domain (S.A. Chuprakov).

Iconics: The Science of Images. Simulation of Attention Zones Based on an Analysis of Local Features of the Image Texture (V.R. Lutsiv and T.A. Novikova); Relationships of Threshold Contrasts of Visual Stimuli in Photopic, Mesopic, and Scotopic Brightness Ranges (L.N. Aksyutov).

Optical Instrumentation and Technology. Use of the Nanoimprint Method for a Single Replication of Polymer Fresnel Optics and Micro-Optics (N.N. Aref'eva and I.Yu. Denisyuk); Technology of Two-Sided Machining of High-Precision ThinCenter Lenses (A.S. Kozeruk, V.F. Klimovich, A.A. Sukhotskiur, and I.P. Filonov); Adaptive Lenses Based on Liquid Crystals (G.E. Nevskaya and M.G. Tomilin); Inertial Stepping Positioner of an Optical Microscope (E.Yu. Buslov, B.A. Zon, A.A. Churikov, and V.A. Shul'gin).

Compiled by L. V. Enushevskaya

Translated by S. Belov 